121 ASSOCIATION OF SPINOPELVIC ALIGNMENT, LOWER EXTREMITY ALIGNMENT, HAMSTRING TIGHTNESS, LOWER EXTREMITY RANGE OF MOTION WITH LANDING PATTERNS IN BALLET DANCERS, FOLK DANCERS AND FOOTBALL PLAYERS

${ }^{1}$ Neslihan Aksu, ${ }^{1}$ Vefa Atansay, ${ }^{2}$ Busra Akgonul, ${ }^{1}$ Ayhan Nedim Kara, ${ }^{3}$ Azmi Hamzaoglu. ${ }^{1}$ Demiroğlu Bilim University Medical Faculty Florence Nightingale Hospital Orthopedics and Traumatology Department, Istanbul, Turkey; ${ }^{2}$ Sisli Florence Nightingale Hospital Physical Therapy and Rehabilitation Department, Istanbul, Turkey; ${ }^{3}$ Istanbul Florence Nightingale Hospital Orthopaedic and Spine Center, Istanbul, Turkey

10.1136/bjsports-2021-IOC.113

Background Dancers are exposed to ACL injuries less than other athletes despite jumping more than other athletes.

Objective To reveal the differences between professional dancers and athletes by posture analysis (coronal and sagittal balances) using EOS X-ray-imaging system and landing patterns after jumps using Kinovea video analysis.

Design Comparative study.

Setting Professional folk and ballet dance groups and Premier League football players.

Patients (or Participants) Volunteered 8 professional folk dancers, 8 professional ballet dancers and 8 premiere league football players.

Interventions (or Assessment of Risk Factors) Hamstring tightness, increased pelvic incidence and thoracal kyphosis angles and decreased ROM are the risk factors for ACL injury during landing.

Main Outcome Measurements Hip, knee and ankle mean ROMs, SLR (straight leg raise) and frontal mechanical axis angle were significantly different between dancers group and athletes group $(p<0.05)$. The mean $P$ incidence angle and mean thoracal kyphosis angle in football players were significantly higher than dancer groups $(\mathrm{p}<0.05)$.

Results Folk dancers use heel, ballet dancers use forefoot and football players use midfoot landings at initial ground contact. Compared to dancers, football players have less trunk, hip, knee flexion degrees at initial ground contact on landing.

Conclusions Hamstring tightness, decreased lower extremity ROMs, trunk flexion, hip flexion, knee flexion during landing may increase ACL injury risk in football players. Optimal hamstring flexibility is very important for preventing injuries in football player, and it also helps athletes improve football-specific skills, such as sprinting, jumping, agility and kicking. These results support the rationale that muscle flexibility ought to be part of the specific training of football players.

\section{EFFECTS OF HAMSTRING FLEXIBILITY AND INCREASED RANGE OF MOTION SINCE CHILDHOOD ON SPINAL AND PELVIC SAGITTAL BALANCE AND LOWER EXTREMITY ALIGNMENT: AN EOS X-RAY-IMAGING SYSTEM ANALYSIS IN DANCERS AND FOOTBALL PLAYERS}

\footnotetext{
${ }^{1}$ Neslihan Aksu, ${ }^{1}$ Vefa Atansay, ${ }^{2}$ Busra Akgonul, ${ }^{1}$ Ayhan Nedim Kara, ${ }^{3}$ Azmi Hamzaoglu. ${ }^{1}$ Demiroğlu Bilim University Medical Faculty Florence Nightingale Hospital Orthopedics and Traumatology Department, Istanbul, Turkey; ${ }^{2}$ Sisli Florence Nightingale Hospital Physical Therapy and Rehabilitation Department, Istanbul, Turkey; ${ }^{3}$ Istanbul Florence Nightingale Hospital Orthopedic and Spine Center, Istanbul, Turkey
}

Background Posture is one of the important factors for body balance. For example, elderly's increased thoracal kyphosis causes them to fall due to sagittal balance disturbance. At the same time, increased valgus axle on lower extremity increases risk of ACL injury during landing. We aimed to research posture changes that may increase the risk of injuries in dancers and athletes and its relationship with SLR and year of sports/ dance.

Objective We intend to reveal the postural differences between professional dancers and athletes by assessment of spinopelvic alignment and lower extremity alignment using EOS X-rayimaging system. We examined SLR (Straight Leg Raise test), and lower extremity ROMs.

Design Prospective comparative study.

Patients (or Participants) 16 professional dancers and 16 Premier League football players.

Interventions (or Assessment of Risk Factors) Increased hamstring tightness increases pelvic incidence and thoracal kyphosis and also increases spinal sagittal balance in positive way that becomes important risk factor of injuries.

Main Outcome Measurements Dancers' lower extremity (hip, knee, ankle) ROMs are significantly higher than athletes $(p<0.05)$. The mean Pelvic incidence angle and mean thoracal kyphosis angle in football players higher $(\mathrm{p}<0.043, \mathrm{P}<0.01)$, mean SLR were significantly lower $(p=0.0001)$ than dancer groups. Dancers' right and left lower extremity valgus axis values were statistically much higher than in football players $(\mathrm{p}=0.015, \mathrm{p}=0.006)$.

Results We observed positive statistical differences between SLR and year of work values $(r=0.704 p=0.0001)$ for dancers and athletes. We observed negative statistical differences between thoracal kyphosis and year of work values $(r=-0.415$, $\mathrm{p}=0.018$ ) for dancers and athletes.

Conclusions In comparison of dance and football training that started in early ages, dance training causes increased ROMs and hamstring flexibility, decreased pelvic incidence and thoracal kyphosis. Therefore, it supports upright and balanced spine and decreases the risk of injuries.

\section{RETURN TO DANCE FOLLOWING ARTHROSCOPIC KNEE SURGERIES: WHAT ARE THE DIFFERENCES BETWEEN RETURN TO SPORT AND RETURN TO DANCE}

${ }^{1}$ Neslihan Aksu, ${ }^{1}$ Vefa Atansay, ${ }^{2}$ Busra Akgonul, 'Bugra Ayaz, ${ }^{1}$ Ayhan Nedim Kara, ${ }^{3}$ Azmi Hamzaoglu. ${ }^{1}$ Demiroglu Bilim University Medical Faculty Florence Nightingale Hospital Orthopedics and Traumatology Department, Istanbul, Turkey; ${ }^{2}$ Sisli Florence Nightingale Hospital Physical Therapy and Rehabilitation Department, Istanbul, Turkey; ${ }^{3}$ Istanbul Florence Nightingale Hospital Orthopedic and Spine Center, Istanbul, Turkey

\subsection{6/bjsports-2021-IOC.115}

Background Due to risk of reinjury and osteoarthritis, timing of return back to level 1 (jumping, pivoting and hard cutting) sports after surgeries is important. Dance injuries are much like sports injuries and literature is not available on the time to return to dance, rate of reinjury and osteoarthritis following arthroscopic surgery.

Objective In this study, we investigated rates of osteoarthritis and reinjury following arthroscopic knee surgery in folk dancers.

Design Retrospective clinical study.

Setting Professional folk dance group. 